\title{
Clinical pathology of acute necrotising pancreatitis
}

\author{
I NORDBACK, ${ }^{*}$ K LAUSLAHTI $\dagger$ \\ From the Department of ${ }^{*}$ Surgery and $\dagger$ Pathology, University Central Hospital of Tampere, Finland
}

SUMMARY Seventy nine pancreatic specimens were obtained from patients treated with pancreatic resection for acute necrotising pancreatitis. The necrotising process had started in the periphery of the gland, so that eight of seventy nine cases contained peripancreatic (mainly fat) necrosis only without any parenchymal necrosis. Peripheral parenchymal necrosis was characterised by a severe inflammatory reaction, with multinucleated leucocytes and microabscess. In the deep parts of the pancreas coagulation necrosis was found. Vascular changes (thrombosis, vessel necrosis) correlated with postoperative haemorrhagic complications, but they did not seem to have had any important role in the necrotising process. The vascular changes seemed to be a secondary phenomenon. In clinical practice the most important aspects in reporting the histology of acute necrotising pancreatitis are the extent of parenchymal necrosis, because the surgeon may overestimate its extent, and the existence of vascular changes, because of the correlation with postoperative recovery.

In recent years pancreatic resection has become a fairly widespread treatment for acute necrotising pancreatitis, expecially in Europe. ${ }^{1-6}$ The precise indications and contraindications for the procedure are, however, far from clear. The aim of pancreatic resection is to reduce the amount of necrotic tissue, to cut down the release of toxic substances, and to reduce the likelihood of infection. Whether the incidence of these sequences of pancreatitis is most effectively reduced is not yet known. For this reason and because severe forms of pancreatitis with necrosis are quite rare most of the workers concerned with this kind of treatment, including pathologists, have as yet very limited experience of the procedure. We had an opportunity to study 79 surgical pancreatic samples obtained by resection from patients with acute necrotising pancreatitis. The correlations between histology and certain clinical variables were investigated in the first 50 patients from whom clinical data were obtainable.

\section{Material and methods}

Seventy nine patients treated between 1973 and 1983 who had undergone pancreatic resection for acute necrotising pancreatis were studied. The age range was 23-75 years (mean 46 years). The aetiology of the pancreatitis was alcohol in 55 cases $(70 \%)$, gallstones in 13 cases $(16 \%)$, and blunt abdominal trauma in

Accepted for publication 29 August 1985 one case. The aetiology of the remaining cases was unknown.

Laparotomy was performed in patients with pancreatitis who deteriorated despite intensive medical treatment and who had signs of peritonitis and in patients with an uncertain diagnosis who were suspected of having visceral perforation. The criterion for pancreatic resection was clear evidence of necrosis of the pancreas based on the macroscopical evaluation made by the surgeon during laparotomy. A left pancreatic resection, starting with splenectomy, was performed, extending to the level of the portal vein or the middle of the head of the pancreas. One pancreaticoduodenectomy was performed.

The specimens were immediately fixed in formalin or frozen in liquid nitrogen. Four to eight transverse sections were taken at regular intervals throughout the pancreatic specimen, the number depending on its length. This dissection was carried out after fixing in formalin, or while the specimens were still frozen; in the latter case the tissue slices were then thawed in formalin at room temperature to ensure simultaneous fixing. Routine paraffin sections were processed and stained with hematoxylin and eosin and with Herovici stain for identification of connective tissue. ${ }^{7}$

Necrosis in the specimen was evaluated in each slice as a percentage of the necrosis in the whole section in both parenchymal tissue (acini and islets) and parapancreatic tissue (fat and fibrous connective tissue, which was either peripancreatic or septal). The mean percentage of the different slices was calculated for each patient and placed on a semiquantitative scale of 


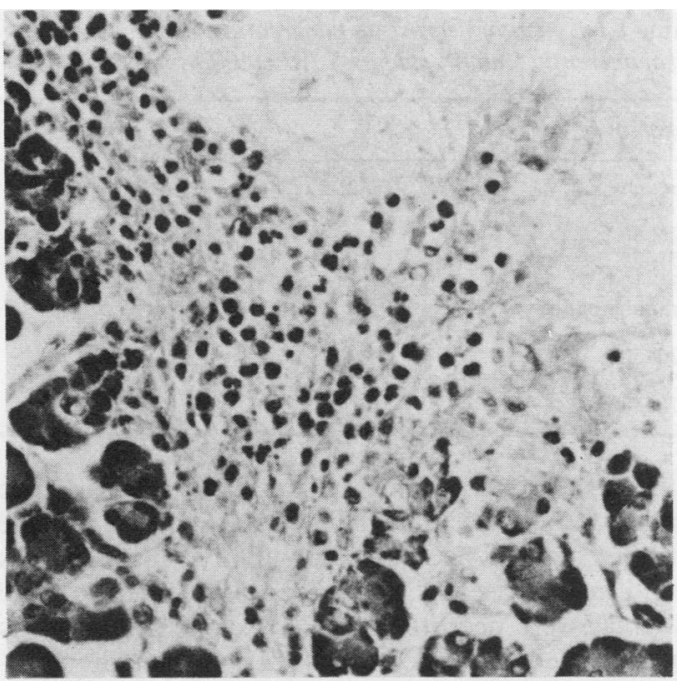

Fig. 1 Inflammatory reaction spreading through interlobular septum from peripancreas into pancreas. Peripancreatic fat is necrotic (top right). Acinar structures seem swollen with interstitial accumulation of fluid. $\times 500$.
$0-25 \%, 26-50 \%, 51-75 \%$, and $76-100 \%$.

Histological assessment was carried out in all 79 cases. Data on the postoperative course and complications were obtained on the first 50 patients, in whom the clinicopathological correlations were also investigated. Twenty nine cases had to be excluded from the clinical study because the data had not been reliably obtained at the time of investigation. Analysis was carried out using the $\chi^{2}$ test.

\section{Results}

On macroscopical examination black areas or a uniform black covering could be seen on the surface of the specimen. After dissection it was found that in nine cases $(11 \%)$ the whole specimen was dark brown or black, while in the others the black areas were mainly concentrated in the peripheral parts of the specimen. The paler areas of the specimen seemed to be swollen.

On histological examination features of acute pancreatitis were evident in each sample. The interstitial inflammation process was characterised by accumu-

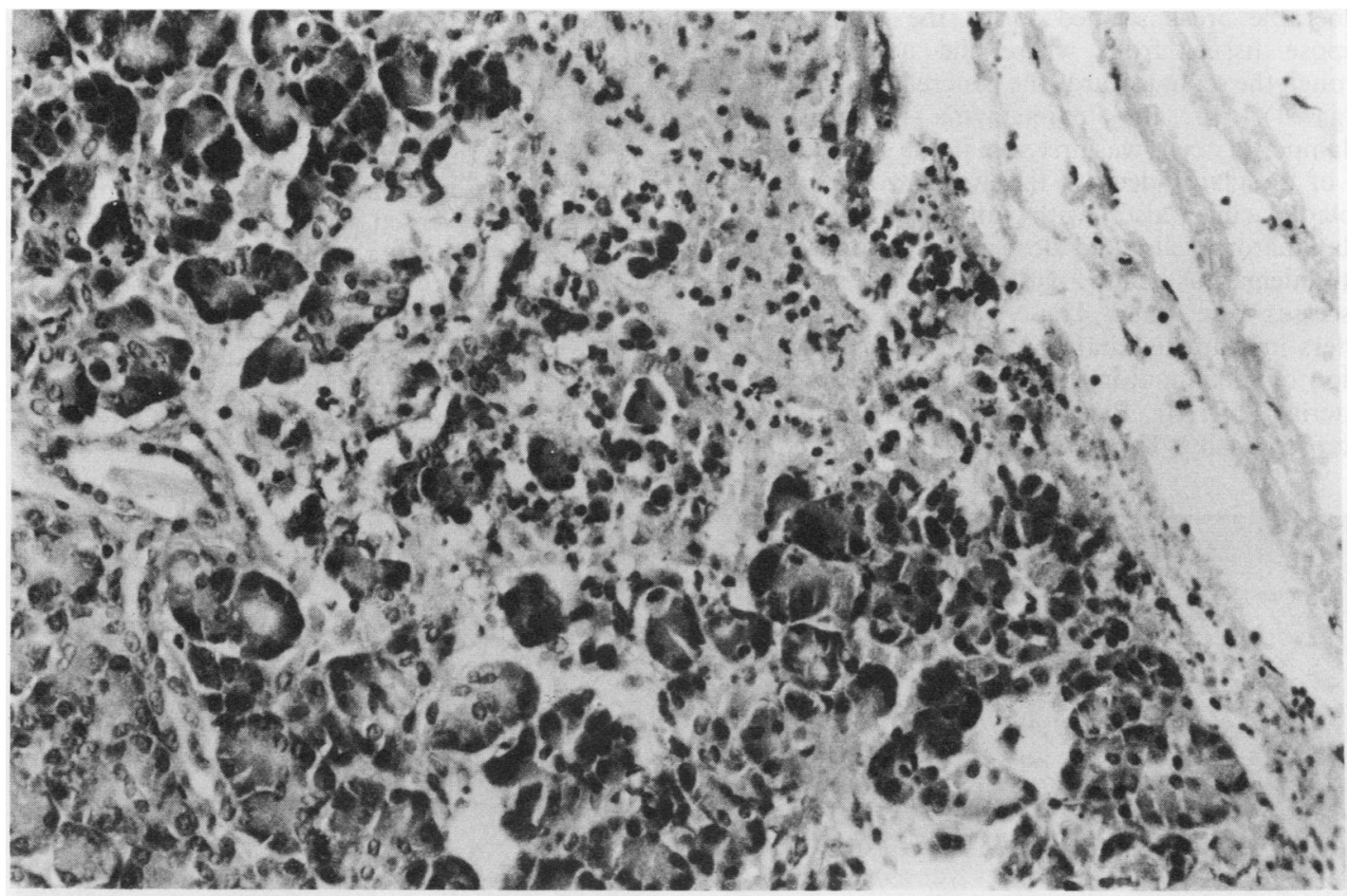

Fig. 2 Staging of pathological changes according to depth. Peripancreatic fat is necrotic haemorrhaged (top right). Most superficial layer of pancreatic parenchyme is necrotic with inflammatory cell reaction (top middle). Next layer contains recently necrotised parenchyme with pycnotic nuclei and disarrangement of structure (top left, bottom right and middle), whereas following layer shows oedematous acinar and ductal structures (bottom left) $\times 500$. 


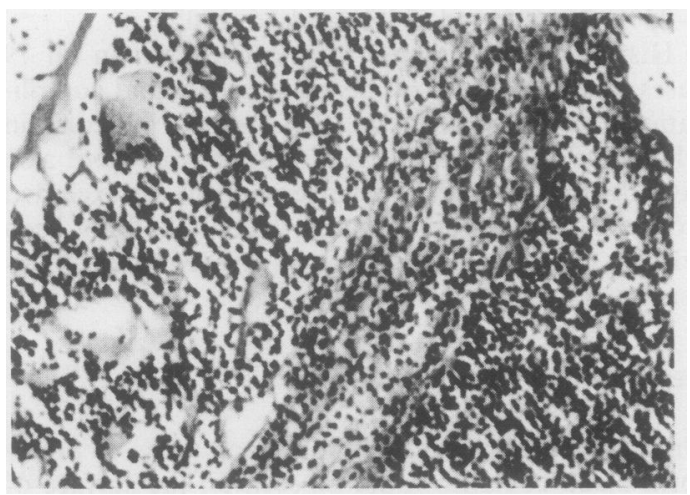

Fig. 3 Microabscess with dense accumulation of inflammatory cells in liquefactive necrosis. $\times 80$.

lation of fluid and leucocytes, of which most were polymorphonuclear. The inflammatory reaction was more severe in the interlobular spaces and septal tissue than within lobules, giving an impression of inflammation starting from the peripheral parts of the gland and protruding through the septa into the deeper parts (Fig. 1).

In each case cell necrosis was also found. The most vulnerable areas seemed to be the peripancreatic adipose tissue, from where the necrosis spread through the septa towards the pancreatic parenchyma (Fig. 1). In the parenchyma necrosis with inflammatory cells was first seen in the superficial layers of the gland; deep to this were swollen and disrupted acini, also with an accumulation of inflammatory cells; and deeper still were preserved but oedematous acini (Fig. 2). In some cases microabscesses were found. These were areas a few millimeters in diameter that contained a dense accumulation of inflammatory cells, exudate, and fibrinous material (Fig. 3). Bacteria could not be detected microscopically. Thus the presence of inflammatory

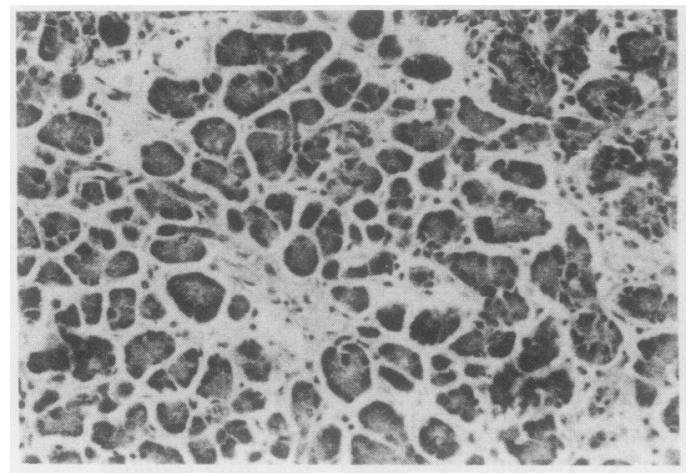

Fig. 4 Coagulation necrosis in middle of pancreas with slightly increased amount of connective tissue. $\times 200$.
Table 1 Extent of necrosis in pancreatic parenchymal and parapancreatic (mainly adipose) tissue in 79 patients studied

\begin{tabular}{lc}
\hline Degree of necrosis (\%) & No of patients (\%) \\
\hline Parenchymal: & \\
$0-25$ & $38(48)$ \\
$26-50$ & $10(13)$ \\
$51-75$ & $11(14)$ \\
$76-100$ & $20(25)$ \\
Parapancreatic: & \\
$0-25$ & $5(6)$ \\
$26-50$ & $9(11)$ \\
$51-75$ & $19(24)$ \\
$76-100$ & $46(58)$ \\
\hline
\end{tabular}

cells was especially typical of superficial necrosis. The occurrence of vascular changes was no prerequisite for this type of necrosis. Coagulative necrosis was found in the cases in which the deeper layers of the pancreas were necrotic (Fig. 4). Acinar necrosis was not detected in 8 cases $(10 \%)$, although parapancreatic necrosis had occurred. Table 1 summarises the distribution of the extent of necrosis in cases studied.

The vascular changes were numerous. Thrombosing vasculitis with segmental necrosis of the vessel wall was a common finding; the affected vessels were small arteries, arterioles, and capillaries. In contrast, thrombosis without phlebitis was noticed in the veins Haemorrhages were almost always found, the most severe being clearly associated with disruption of the vessel wall due to necrosis (Fig. 5). Table 2 shows the incidence of these histological changes. In some of the specimens an increased amount of connective tissue was seen; necrosis was also found in these specimens.

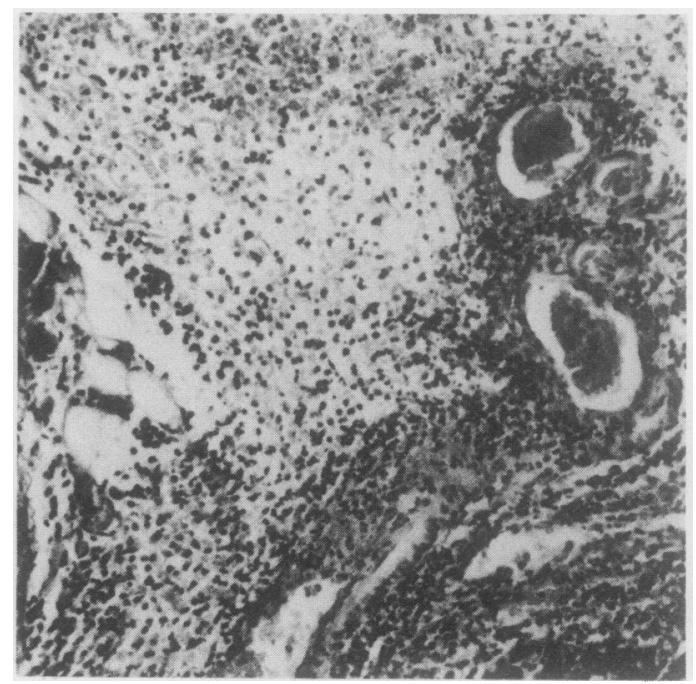

Fig. 5 Necrotising vasculitis and vascular wall disruption followed by severe haemorrhage and secondary accumulation of inflammatory cells. $\times 200$. 
Table 2 Histological findings in pancreatic specimens from 79 patients studied with acute necrotising pancreatitis

\begin{tabular}{lc}
\hline Histological findings & No of patients (\%) \\
\hline Parenchymal necrosis & $71(90)$ \\
Parapancreatic necrosis & $79(100)$ \\
Increased amount of connective tissue & $18(23)$ \\
Microabscesses & $5(6)$ \\
Intravasal thrombosis & $68(86)$ \\
Vascular wall necrosis & $38(48)$ \\
Haemorrhages & $71(90)$ \\
\hline
\end{tabular}

Calcium deposits, flattened epithelium, or dilated ducts were not found.

No histological difference was found between the various aetiological groups (gallstones, alcohol, unknown). Table 3 shows that the extent of extensive parenchymal necrosis was proportional to the length of time from onset of symptoms until operation. The severity of vascular necrosis increased in the early stages of pancreatitis but then decreased as the symptoms persisted.

Nineteen of the first 50 patients died $(38 \%)$. Three died from cardiac arrest, one from liver necrosis, one from bone marrow depression, and one from renal failure and pneumonitis of toxic origin. The main cause of death was sepsis (seven patients), which started as an abscess in the region of the pancreas. Only one of the patients with microabscesses in the pancreas, however, developed a postoperative abscess. Of the eight cases of postoperative abscess, three occurred in glands with under $50 \%$ parenchymal necrosis and five in glands with over $50 \%$ parenchymal necrosis. Six patients died from postoperative haemorrhage. Haemorrhage was the only histological variable that correlated significantly with mortality; $p$ $<0.001$ (Table 4). Altogether, 17 patients required further surgery for postoperative haemorrhage arising in the operated area. Histological evidence of necrosis and haemorrhage seemed to predict a higher
Table 4 Mortality in relation to histological changes in 50 patients treated with pancreatic resection for acute necrotising pancreatitis

$\left.\begin{array}{llc}\hline & & \text { Mortality }(\%) \\ \hline \text { Pancreatic parenchymal necrosis } & <50 \% & 11 / 34(32) \\ & >50 \% & 8 / 16(50) \\ \text { Parapancreatic necrosis } & <50 \% & 3 / 12(25) \\ & >50 \% & 16 / 38(42) \\ \text { Increased amount of } & \text { Yes } & 5 / 15(33) \\ \text { connective tissue } & \text { No } & 14 / 35(40) \\ & \text { Yes } & 3 / 5(60) \\ \text { Microabscesses } & \text { No } & 16 / 45(36) \\ & \text { Yes } & 15 / 43(35) \\ \text { Vascular thrombosis } & \text { No } & 4 / 7(57) \\ & \text { Yes } & 9 / 24(38) \\ \text { Vascular wall necrosis } & \text { No } & 10 / 26(38) \\ & \text { Yes } & 19 / 48(40) \\ \text { Haemorrhages } & \text { No } & 0 / 2\end{array}\right\}(\mathrm{p}<0.001)$

*Total mortality $19 / 50(38 \%)$.

Table 5 Histological vascular changes and incidence of reoperation required for postoperative haemorrhage in 50 patients treated with pancreatic resection for acute necrotising pancreatitis

Patients requiring reoperation for haemorrhage

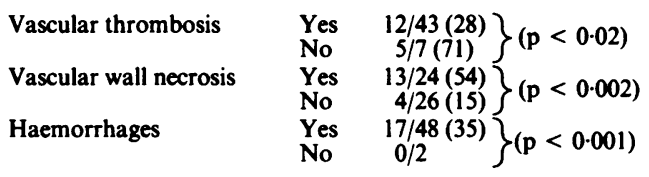

risk of postoperative haemorrhage. On the other hand, vascular thrombosis seemed to predict a significantly lower risk of postoperative haemorrhage; $\mathrm{p}<0.02$ (Table 5).

\section{Discussion}

Both the gross pathology and the microscopical

Table 3 Incidence of histological changes occurring between onset of symptoms and date of operation in 50 patients with acute necrotising pancreatitis

\begin{tabular}{|c|c|c|c|}
\hline & \multicolumn{3}{|c|}{ Duration of symptoms } \\
\hline & $<4$ days & 4-7 days & $>7$ days \\
\hline & $(n=30)$ & $(n=9)$ & $(n=11)$ \\
\hline $\begin{array}{l}\text { Over } 50 \% \text { parenchymal necrosis } \\
\text { Over } 50 \% \text { parapancreatic necrosis } \\
\text { Increased amount of connective tissue } \\
\text { Microabscesses } \\
\text { Intravasal thrombosis } \\
\text { Vascular wall necrosis } \\
\text { Haemorrhages }\end{array}$ & $\begin{array}{l}8(27) \\
23(77) \\
10(33) \\
2(7) \\
26(87) \\
11(37) \dagger \\
29(97)\end{array}$ & $\begin{array}{l}1(11)^{*} \\
7(78) \\
1(11) \\
1(11) \\
8(89) \\
8(89)+ \\
8(89)\end{array}$ & $\begin{array}{l}7(64)^{*} \\
8(73) \\
4(36) \\
2(18) \\
9(82) \\
5(45)+\dagger \\
11(100)\end{array}$ \\
\hline
\end{tabular}

Figures in parentheses are numbers $(\%)$.

$*(p<0.001) ;+(p<0.01) ;+t(p<0.02)$. 
appearance of acute necrotising pancreatitis have been described in detail over the past 50 years. $^{8-10}$ Most of the studies were, however, based on studies on animals or necropsy specimens. It is well known that rapid autolysis of the pancreas by the glands digestive enzymes destroys the normal histology of the organ soon after the patient's death. The techniques of immediate fixation or freezing of the pancreas after interruption of its blood supply used in our study have only been possible since the introduction of pancreatic resection for treating acute necrotising pancreatitis. Since Watt's first report in $1963^{11}$ this method has been increasingly used. Nevertheless, only a few reports have been published on the histology of the pancreatic specimen.

In most studies on animals the pathology of necrotising pancreatitis is characterised by liquefactive necrosis with abundant leucocyte infiltration, whereas in pancreatitis in man the necrosis is considered rather as coagulative necrosis from pancreatic infarction. ${ }^{1213}$ Phat et al studied 20 total pancreatectomy specimens from patients with acute necrotising pancreatitis and found both coagulative necrosis and liquefactive necrosis with a severe inflammatory cell reaction. ${ }^{14}$ The histology of the necrosis was essentially similar in our study. Coagulative necrosis was especially common in the inner parts of the pancreas, while in the superficial parenchyma leucocyte infiltration was severe.

The material obtained for this study differs from that used in earlier studies in its aetiological distribution. Usually pancreatitis from gallstones constitutes about two thirds and pancreatitis induced by alcohol one quarter of the diseases. ${ }^{15}$ The distribution in our study, however, represents typical Finnish material, comprising principally men with heavy drinking habits. ${ }^{16}$

The histology of the different aetiological types of pancreatitis agreed with the findings of Phat et al. ${ }^{14}$ Boutelier found necrosis to be caudal in pancreatitis of gallstone or unknown aetiology but diffuse or cephalic in the remaining cases. Diffuse or patchy necrosis was rare among our patients: we found only one case with areas of necrotic and non-necrotic tissue side by side throughout the specimen and considered this to be a diffusely necrotised organ. This might have been, however, only the preliminary stage of total necrosis, because the non-necrotic areas had clearly swollen acini.

Necrosis was seen predominantly in peripancreatic tissue or in the peripheral parts of the pancreas itself, while the inner parts were, in most cases, not necrotic. This poses the surgeon a difficult problem-namely, how to make therapeutic decisions based on the superficial appearance of the organ, which do not seem to correlate with changes deep in the organ.
Overestimation of the extent of necrosis is not uncommon. ${ }^{1819}$ This also explains the high number of cases in this study with pancreatic parenchyma that were not greatly necrotic. We considered the histological biopsy technique suggested by Phat et al $^{14}$ too hazardous because of the possibility of pancreatic fistulae in patients in whom no resection was performed. It is not known whether fine needle aspiration cytology would give useful information.

In studies that analyse necrotising pancreatitis pathoanatomically and pathophysiologically the most interesting aspects are the early histological changes, and the features which distinguish irreversible from reversible damage. In an electron microscopical study Helin et al showed acinar dilatation with accumulation of amorphous material in the lumen of acini, disappearance of microvilli, and swell- $\infty$ ing of the apical parts of the acinar cells. ${ }^{20} \mathrm{We}$ also found considerable swelling and even vacuolisation of acinar cells, especially near the necrotic areas. These changes, together with the loss of adhesion of epithelial cells from their basement membranes, are nonspecific and are to be found in cellular damage of various origins.

The fact that the amount of necrosis increased with the interval from the onset of symptoms suggests a continuation of the necrotising process. Retroperitoneal extension of the necrosis has been documented. ${ }^{21}$ It occurs in about one third of patients, despite pancreatic resection, causing total or partial necrosis of the pancreas remnant. ${ }^{22}$ In two thirds of cases, however, extension of the necrosis ceased; the limiting factors involved are unknown.

It has been suggested that the vascular changes (vasculitis, thrombosis) are responsible for the necrosis, which has hitherto been regarded as pancreatic infarction. ${ }^{23}$ The peripheral or subcapsular onset of parenchymal necrosis may support this vascular hypothesis. In contrast, in this series 27 of $31(87 \%)$ of patients with necrosis of over $50 \%$ of parenchymal tissue had vascular thrombosis, and no difference was found when these were compared with cases with under $50 \%$ parenchymal necrosis (41 of $48(85 \%)$. Indeed, there was one case with multiple thrombosis but without noticeable parenchymal necrosis. Moreover, eight cases with peripancreatic but without pancreatic parenchymal necrosis were found. Thus the theory of necrosis as a consequence of vascular changes seems questionable. Thrombosing vasculitis may equally well be a secondary phenomenon, as suggested by Takada et al. ${ }^{24}$ For experimental pancreatitis we prefer the term "tryptic" or enzymatic lytic necrosis, which describes the role of lipolytic and proteolytic enzymes in the necrotising process. ${ }^{25} \mathrm{We}$ found early and extensive fat necrosis, suggesting an increased function of lipoactive enzymes (lipase, , 
phospholipase $\left.\mathrm{A}_{2}\right){ }^{26}$ The superficial parenchymal necrosis with severe inflammatory reaction resembled that of tryptic necrosis found in certain animal models. ${ }^{1213}$ It has also been suggested that the coagulative necrosis typical of pancreatitis in man found in this study, especially in the inner parts of the pancreas, might be caused by the destruction of cell membrane induced by phospholipase activity. ${ }^{1213}$ Although we do not consider that vascular changes are the basis of the necrosis, systemic circulatory disturbances with hypotension induced by pancreatitis, together with intrapancreatic vascular changes may, however, be important cofactors in the extension of pancreatic necrosis, because the pancreas, like the kidney, is vulnerable to hypoxia. ${ }^{27}$

The prevalence of vascular lesions $(48 \%$ with vessel wall necrosis, $86 \%$ with thrombosis) exceeded that described earlier: the corresponding figures in the necropsy study caried out by Blenkinsopp ${ }^{28}$ (31 cases) were $39 \%$ and $42 \%$, respectively, and those of the study by $\mathrm{Phat}$ et al $^{14}$ (surgical specimen from 20 patients) $40 \%$ and $50 \%$, respectively. Giant cell arteritis ${ }^{14}$ was not found in our patients.

Contrary to widely held belief, Machado et al recently described histologically verified acute necrotising pancreatitis in 12 patients suffering from chronic calcifying pancreatitis. ${ }^{29}$ We made a similar observation in our study, although we prefer the term pancreatic fibrosis rather than chronic pancreatitis, because no clear acinar or ductal changes were found. One patient with symptoms resembling chronic pancreatitis and who had had four acute episodes of oedematous pancreatitis developed acute necrotising pancreatitis with $26-50 \%$ parenchymal necrosis. He also had an appropriately increased amount of connective tissue in the specimen. Moreover, in seventeen other previously symptom free patients an increased amount of connective tissue was observed (total incidence $23 \%$ ). An even higher incidence of pancreatic fibrosis $(23$ of $31,74 \%)$ was observed in necropsy material from patients who died of acute necrotising pancreatitis. ${ }^{28} \mathrm{~A}$ few more patients developed parenchymal necrosis of more than $50 \%$ in the group of patients without $(26$ of $61,43 \%)$ than with (five of 18 , $28 \%$ ) pancreatic fibrosis. This might be taken to mean that a chronically inflamed pancreas is not capable of producing such large amounts of toxic substances as a previously healthy organ.

Interestingly, the only histological feature of prognostic importance was the occurrence of haemorrhages, but, as only two of the 50 patients who were studied clinically had no haemorrhages the finding can not have great discriminatory value. The extent of necrosis was not an important variable: three of eight patients died (mortality $38 \%$ ) without noticeable parenchymal necrosis. Our material, how- ever, comprised only the severe forms of pancreatitis, and thus no comparison could be made with milder forms of the disease. Moreover, the extent of necrosis in the surgical specimen may not closely correlate with the extent of necrosis in the remaining part of the pancreas, which governs the subsequent clinical course.

Microabscesses in the pancreatic specimens did not predict postoperative abscess. The reason might lie in the focal nature of these changes, as well as in the absence of bacteria on microscopy. The correlations between vascular changes and postoperative haemorrhage seemed logical: vascular wall necrosis increased the danger of postoperative haemorrhage and the trend to thrombosis reduced it.

To conclude, in clinical practice the most important points to be specified on the pathology report of the histology of acute necrotising pancreatitis are the extent of pancreatic necrosis, and the presence of vascular damage. The first would be instructive for the surgeon, who may have overestimated the extent of necrosis because of the severity of superficial pancreatic damage. The second correlates with the postoperative clinical course.

\section{References}

${ }^{1}$ Hollender LF, Gillet M, Kohler JJ. Die dringliche Pankreatektomie bei der akuten Pankreatitis. Langenbecks Arch Chir 1971;328:314-27.

${ }^{2}$ Kümmerle F, Neher M, Schönborn H, Mangold G. Vorzeitigen Operation bei Akuten hämorrhagisch-nekrotisierender Pankreatitis. Dtsch Med Wochenschr 1975;100:2241-5.

${ }^{3}$ Frey HP, Meyer W, Miller G, Maurer W. Subtotale distale Pankreatektomie in der Behandlung akuter nekrotisierender Pankreatitiden: Indikation und Resultate. Helv Chir Acta 1978;45:693-8.

4 Jonsel G, Boutelier P. Observations during treatment of acute necrotizing pancreatitis with surgical ablation. Surg Gynecol Obstet 1979;148:385-6.

${ }^{5}$ Alexander J-H, Guerrieri MT. Role of total pancreatectomy in the treatment of necrotizing pancreatitis. World $J$ Surg 1981;5:369-77.

${ }^{6}$ Kivilaakso E, Lempinen M, Mäkeläinen A, Nikki P, Schröder T Pancreatic resection for acute fulminant pancreatitis. A randomized controlled study. Ann Surg 1984;199:426-31.

${ }^{7}$ Herovici C. Polychrome stain for differentiating precollagen from collagen. Stain Technol 1963;38:204-6.

${ }^{8}$ Quick B. Acute pancreatitis. Aust NZ J Surg 1932;2:115-40.

${ }^{9}$ Popper HL, Necheles H, Russel KC. Transitional of pancreatic edema into pancretic necrosis. Surg Gynecol Obstet 1948;87:79-82.

${ }^{10}$ Thal AP, Perry JF Jr, Egner W. A clinical and morphological study of forty-two cases of fatal acute pancreatitis. Surg Gynecol Obstet 1957;105:191-202.

${ }^{11}$ Watts GT. Total pancreatectomy for fulminant pancreatitis. Lancet 1963;ii:384.

${ }^{12}$ Creutzfelt W, Schmidt $H$. Aetiology and pathogenesis of pancreatitis. Scand J Gastroenterol 1970;5:47-62.

${ }^{13}$ Anonymous. Mechanism of pancreatic autodigestion. [Editorial]. $N$ Engl J Med 1970;283:487-8.

${ }^{14}$ Phat VN, Guerrieri MT, Alexander JH, Camilleri JP. Early histological changes in acute hemorrhagic necrotizing pancreatitis. A 
retrospective pathological study of 20 total pancreatectomy specimens. Path Res Pract 1984;178:273-9.

${ }^{15}$ Banks PA. Pancreatitis. New York: Plenum, 1979.

${ }^{16} \mathrm{Kyösola} \mathrm{K}$, Fock G. The aetiology of acute pancreatitis. Annales Chirurgiae et Gynaecologiae Fenniae (Supplementum) 1976;65:3-6.

${ }^{17}$ Boutelier P. Les lesions macroscopiques dans les pancréatites aiguës nécrosantes: Modalité et difficultés d'exploration chirurgicale. Essai de classification. Ann Chir 1972;26:243-8.

${ }^{18}$ Leger L, Chiche B, Louvel A. Pancreatic necrosis and acute pancreatitis. World J Surg 1981;5:315-7.

${ }^{19}$ Nordback I, Pessi T, Auvinen O, Autio V. Determination of necrosis in necrotizing pancreatitis. Br J Surg 1985;72:225-7.

${ }^{20}$ Helin H, Mero M, Markkula H, Helin M. Pancreatic acinar ultrastructure in human acute pancreatitis. Virchow Arch (Pathol Anat) Histol 1980;387:259-70.

${ }^{21}$ MacLean N. The role of surviving pancreas in late fatalities of acute pancreatitis. Br J Surg 1977;64:345-6.

${ }^{22}$ Nordback I, Auvinen O, Pessi T, Autio V. Complications after pancreas resection for acute necrotizing pancreatitis. Acta Chir Scand (in press).

${ }^{23}$ Schmitz-Moorman P. Comparative radiological and morphological study of the human pancreas. IV. Acute necrotizing pancreatitis in man. Path res Pract 1981;171:325-35.

${ }^{24}$ Takada Y, Appert HE, Howard JM. Vascular permeability induced by pancreatic exudate formed during acute pancreatitis. Surg Gynecol Obstet 1976;143:779-83.

${ }^{25}$ Becker V. Pathological anatomy and pathogenesis of acute pancreatitis. World J Surg 1981;5:303-13.

${ }^{26}$ Zieve L, Vogel WC, Kelly WD. Species difference in pancreatic lipolytic and amylolytic enzymes. J Appl Physiol 1963;18:77-82.

${ }^{27}$ Warshaw AL, O'hara PJ. Suspectibility of the pancreas to ischemic injury in shock. Ann Surg 1978;188:197-201.

${ }^{28}$ Blenkinsopp WK. The liver and pancreas in acute necrotizing pan- है creatitis. J Clin Pathol 1978;31:791-3.

${ }^{29}$ Machado MCC, da Cunha JEM, Bacchella T, de Barros Mott C, Duarte I, Bettarello A. Acute pancreatic necrosis in chronic alcoholic pancreatitis. Dig Dis Sci 1984;29:709-13.

Requests for reprints to: Dr I Nordback, Department of oSurgery, University Central Hospital of Tampere 33520 Tampere, Finland. 